УДК 314.15

$10.17213 / 2075-2067-2021-2-21-28$

\title{
РЕСУРСЫ РОССИЙСКОЙ ПРОНАТАЛИСТСКОЙ ПОЛИТИКИ: КЛАССИФИКАЦИЯ И МЕТОДИЧЕСКИЕ ПРИНЦИПЫ ИССЛЕДОВАНИЯ ${ }^{1}$
}

\section{(C) 2021 г. A. П. Багирова}

Уральский федеральный университет имени первого Президента России Б. Н. Ельцина, 2. Екатеринбург, Россия

Целью исследования выступает разработка теоретико-методологических основ ресурсного подхода к изучению и реализации российской пронаталистской политики.

Методология исследования строится на системном анализе ресурсов, институциональном подходе, используемом в демографии.

Результаты исследования состоят в классификачии и характеристике ресурсов демографической политики, направленной на повымение рождаемости, в разработке методологических подходов к их изучению.

Перспективы исследования предполагают разработку и реализаџию методик исследования ресурсов каждого вида, оценку потенциала этих ресурсов в достижении иелей российской пронаталистской политики.

Ключевые слова: демографическая политика; пронаталистская политика; рождаемость; ресурсы.

\section{RESOURCES OF THE RUSSIAN PRONATALIST POLICY: CLASSIFICATION AND METHODOLOGICAL PRINCIPLES OF RESEARCH}

\author{
(C) 2021 A. P. Bagirova \\ Ural Federal University named after the first President of Russia B. N. Yeltsin, \\ Yekaterinburg, Russia
}

The aim of the research is to develop the theoretical and methodological foundations of the resource approach to the study and implementation of the Russian pronatalist policy.

The research methodology is based on a systematic analysis of resources, an institutional approach used in demography.

The results of the study consist in the classification and characterization of the resources of demographic policy aimed at increasing the birth rate, in the development of methodological approaches to their study.

The prospects of the research suggest the development and implementation of methods for the study of resources of each type, the assessment of the potential of these resources in achieving the goals of the Russian pronatalist policy.

Key words: demographic policy; pronatalist policy; fertility; resources.

1 Исследование проведено в рамках проекта «Российская пронаталистская политика: ресурсы, эффекты, возможности оптимизации», поддержанного Советом по грантам Президента Российской Федерации на государственную поддержку ведущих научных школ Российской Федерации (НШ-2722.2020.6). 
Введение. В настоящее время в России проводится активная пронаталистская политика. Ее основные задачи и средства реализации указаны в паспорте национального проекта «Демография», которым предусмотрены меры поддержки семей с детьми экономического, информационного, организационного характера [13]. Представляется, что эффективность государственной демографической политики могла бы быть выше, если бы подход к рассмотрению потенциальных ресурсов для ее реализации был шире. Например, государственные цели повышения рождаемости сегодня могут быть поддержаны и на мезоуровне. В качестве институтов стимулирования рождаемости на этом уровне могут рассматриваться институты гражданского общества (например, общественные организации), институт религии, социальный институт бизнеса и т.д.

Расширенный подход к ресурсам демографической политики лежит в русле институционального подхода в демографии [9], который признает открытым признаковое пространство, используемое для описания демографического развития, допускает использование категорий, отражающих специфику отдельно взятого региона, исходит из нестабильной структуры детерминации демографического развития, а внутреннюю логику регионального развития признает его существенным фактором, исходя из равенства «глобального» и «регионального» [9]. С этой точки зрения приоритетной становится задача изучения многообразия и многофакторности демографических процессов в регионах [16], поскольку только регулирование на основе понимания региональной специфики позволит реализовать задачи государственной демографической политики в целом.

Определение и классификации ресурсов пронаталистской политики. В качестве ресурсов пронаталистской политики нами предлагается понимать те средства и условия, которые позволили бы с помощью определенных преобразований достигать целей этой политики. По нашему мнению, ресурсы демографической пронаталистской политики могут быть классифицированы по нескольким основаниям:

1) уровень их реализации - федеральный, субъектов РФ, местный;
2) институциональный разрез - социальные институты семьи, образования, культуры, бизнеса, труда, гражданского общества и т.д.;

3) сфера формирования - демографическая, правовая, культурная, информационная, экономическая и т.д.;

4) средовый разрез - городская и сельская среда, информационно-коммуникационная, технологическая, природная среда.

Учитывая многомерность классификаций ресурсов пронаталистской политики, важно отметить, что каждый конкретно взятый инструмент этой политики одновременно выступает элементом ресурсов, выделенных по разным основаниям: по уровню реализации, сфере, среде и социальному институту, в котором этот инструмент формируется и функционирует.

Охарактеризуем некоторые из перечисленных видов ресурсов.

Экономические ресурсы пронаталистской политики - это наиболее активно используемые сегодня экономические инструменты ее реализации $[5,7]$. Их источниками выступают средства федерального бюджета и бюджетов субъектов РФ, расходуемые в рамках направлений достижения цели этой политики.

В качестве демографических ресурсов пронаталистской политики предложено рассматривать две группы населения: молодежь репродуктивного возраста - потенциальных и «действующих» родителей; старшее поколение - потенциальных и «действующих» бабушек и дедушек, которые имеют временны́е ресурсы для заботы о внуках и помощи своим детям в выполнении их родительских функций [10].

Правовые ресурсы пронаталистской политики - те юридические инструменты, с помощью которых создаются условия, благоприятствующие рождаемости и оказывающие влияние на принятие населением репродуктивных решений. Так, например, отпуск по беременности и родам, отпуск по уходу за ребенком до достижения им определенного возраста во многих странах мира рассматривается в качестве важнейших мер государственной демографической политики [2]. Государственное регулирование этих отпусков определяет взаимоотношения ключевых стейкхолдеров демографической полити- 
ки - населения репродуктивного возраста, государства, работодателей.

Социальный институт бизнеса, рассматриваемый как ресурс пронаталистской политики, может создавать условия для поддержки мер этой политики. Стимулирование рождаемости и родительства через социальный институт бизнеса способно дополнить государственное стимулирование и сделать его более адресным с учетом потребностей конкретных работников организаций, выполняющих родительские функции одновременно с профессиональными. Корпоративная демографическая политика, выступая составной частью социальной ответственности, может компенсировать недостаточность оказываемой государством помощи семьям с детьми и усилить оказываемую в области родительства поддержку на макроуровне [17]. При этом государство способно активизировать корпоративную демографическую политику организаций комплексом мер (благоприятный налоговый режим, субсидии и льготы и т.д.).

Информационные ресурсы пронаталистской политики - это возможности, которые предоставляют средства массовой информации для продвижения целей демографической политики, а также контент, содержащийся в тематических сообществах социальных сетей. По мнению целого ряда ученых, сегодня социальные сети являются наиболее чуткой реакционной цифровой средой, отражающей различные социальные явления и процессы [18].

Социальный институт труда, рассматриваемый в качестве ресурса пронаталистской политики, - это понимаемая в широком смысле сфера труда. В частности, сюда предложено относить не только трудовую деятельность на рынке труда, но и родительский труд $[6,15]$. Этот вид труда соответствует таким принципам трудовой деятельности, как осознанность действий, их целесообразность, результативность, общественная полезность и энергозатратность. Оба вида труда имеют свои субъекты, цели, задачи и мотивы, технологии реализации. В отношении каждого из этих видов труда можно говорить в терминах его организации и стимулирования. Говорить о родительском труде как социальном институте нам позволяет то, что он основан на устойчивом комплексе формальных и не- формальных правил, принципов, норм, установок, которые регулируют взаимодействие людей в сфере родительского труда и организуют его в систему ролей и статусов.

Гармонизация сфер профессионального и родительского труда напрямую связана с достижением задач пронаталистской политики. Высокая значимость этой проблемы и важность ее решения для нашей страны отражена в одном из федеральных проектов, входящих в национальный проект «Демография» - «Содействие занятости женщин создание условий дошкольного образования для детей в возрасте до трех лет». Цель этого федерального проекта состоит в обеспечении возможностей женщин, имеющих детей, совмещать трудовую деятельность с семейными обязанностями.

Социальному институту семьи, рассматриваемому в качестве ресурса пронаталистской политики, посвящены работы многих отечественных и зарубежных ученых $[8,12]$. Сегодня общепризнанно, что семья и имеющиеся у нее ресурсы играют существенную роль в процессе формирования и развития человеческого капитала детей. От эффективности этого процесса зависят успешное развитие ребенка, его воспитание, духовнонравственные ценности и др. В свою очередь фактические вложения семьи в развитие человеческого капитала детей тоже находятся под влиянием целого ряда факторов: объем и качество различных ресурсов семьи, желание родителей развивать своих детей, государственная поддержка семей с детьми и т.д. Из совокупности ресурсов, необходимых семье для реализации родительского труда, можно выделить материальные, трудовые (физические и временны́е) и моральные. Исследование материальных затрат, связанных с родительством и родительским трудом, крайне актуально в связи с тем, что, несмотря на противоречивые результаты научных исследований о взаимосвязи экономического уровня жизни населения и рождаемости, большинство политик по поддержке рождаемости строятся прежде всего на экономических мерах [14]. В рамках изучения трудовых ресурсов семьи чаще всего исследуются временны́е затраты на реализацию родительского труда. Интересным аспектом изучения может выступить исследование временны́х 
ресурсов расширенного субъекта родительского труда: учитывая то, что функции родительского труда могут быть реализованы не только родителями, но и бабушками, дедушками, другими родственниками, изучение содержания и затрат времени на их труд также должно учитываться в общей оценке временны́х ресурсов семьи, затрачиваемых на детей.

Городская среда мегаполиса также может рассматриваться в качестве ресурса пронаталистской политики [3]. Это связано с тем, что городская среда в современном понимании - это комплекс взаимосвязанных условий - естественно-природных и искусственно созданных, материальных и нематериальных, вещных и не-вещных. Городская среда предстает как среда для реализации жизнеобеспечивающих (физическое существование и воспроизводство, сохранение здоровья, безопасность) и жизнедеятельностных (работа, повседневные рутинные и потребительские практики, коммуникация, образование, культурное развитие, отдых) потребностей населения. Практические возможности реализации разнообразных потребностей характеризуют определенное качество городской среды, которое в масштабе мегаполиса не является однородным.

Исследования, посвященные анализу городской среды как среды для воспроизводства и развития человеческого капитала, приобретают особую ценность в условиях острой конкуренции крупных городов за привлечение и удержание человеческих ресурсов.

Методологические подходы к изучению ресурсов пронаталистской политики. Учитывая многомерность классификаций и разнообразие видов ресурсов пронаталистской политики, в качестве методологических подходов к их исследованию, на наш взгляд, следует выделять следующие подходы.

1) Дифференциация каждого вида ресурса на подвиды для целей изучения характера их влияния на цели пронаталистской политики.

Например, демографические ресурсы могут быть классифицированы по группам населения (по полу, возрасту, наличию детей, занятости и т.д.). Правовые ресурсы демографической пронаталистской политики различаются по отраслям права - они мо- гут лежать в области семейного, трудового, гражданского, административного законодательства. Разные виды ресурсов социального института бизнеса объединяются единым источником их финансирования - средства хозяйствующих субъектов. Информационная среда формирования ресурса пронаталистской политики включает в себя не только сферу государственной информационной политики, но и тексты тематических сообществ в социальных сетях, оказывающие в современном мире серьезное влияние на молодые когорты населения.

2) Многообразие методов оценки эффективности использования ресурсов пронаталистской политики.

Вопрос методики оценки эффективности политики стимулирования рождаемости является одним из самых дискуссионных в демографической литературе. О том, что он не имеет однозначного решения, говорит, например, О.В. Кучмаева, связывая эту проблему с отсутствием сводной статистической оценки эффективности государственного управления институтом семьи [11]. Есть и другие - более резкие позиции, отрицающие результативность такой политики в силу того, что она не увеличивает число рождений, а лишь сдвигает их на более ранний срок $[1,4]$.

3) Многообразие источников информации, используемых для оценки ресурсов пронаталистской политики.

Дифференциация ресурсов предопределяет целую совокупность источников информации об этих ресурсах. Использование только данных официальной статистики может привести к серьезным ограничениям в исследовании. В процессе изучения ресурсов политики крайне важен субъективный аспект, а именно - оценка населением востребованности отдельных элементов этого ресурса, их достаточности и эффективности. С нашей точки зрения, оценка ресурсов пронаталистской политики может проводиться только на основании совокупности объективных экономико-статистических и субъективных социологических данных. Кроме того, отдельную группу источников составляют тексты документов, регулирующих демографическую политику стимулирования рождаемости, тексты (посты) в тематических сообществах в социальных сетях. 
4) Использование совокупности показателей для измерения уровня востребованности населением того или иного вида ресурса пронаталистской политики.

Показатели, характеризующие уровень востребованности ресурсов, могут быть разделены на прямые и косвенные. К прямым показателям относятся, например, показатели расходования средств бюджетов на те или иные пособия, оценки удовлетворенности населения, получающего или пользующегося конкретными видами ресурсов. Косвенные показатели востребованности ресурсов пронаталистской политики - это индикаторы, измеряющие уровень и качество жизни потенциальных пользователей этих ресурсов, т.е. индикаторы результата, к которому приводит использование того или иного ресурса. В качестве косвенных показателей могут рассматриваться, например, общая площадь жилых помещений, приходящаяся в среднем на одного жителя (поскольку ресурсы демографической пронаталистской политики направлены на улучшение жилищных условий семей с детьми), обеспеченность детей дошкольного возраста местами в детском саду (поскольку меры демографической политики предполагают повышение этого показателя) и т.д.

Заключение. Понимание и системное описание всего многообразия ресурсов, которые могут быть использованы при реализации пронаталистской политики, позволит более четко планировать их использование и достижение тех амбициозных целей, которые эта политика преследует. Перспективы же дальнейшего исследования демографической политики с точки зрения ресурсного подхода видятся нам в разработке и реализации методик исследования ресурсов каждого вида, оценке потенциала этих ресурсов в достижении целей пронаталистской политики в отдельных российских регионах.

\section{Литература}

1. Demeny P. Population Policy // International Encyclopedia of Population. - New York, MacMillan Reference, 2006. — Pp. 752-763.

2. Koslowski A., Blum S., Dobrotić I., Kaufman G., Moss P. International Review of Leave Policies and Research 2020 [Electronic re- source]. — URL: http://www.leavenetwork.org/ lp_and_r_reports/ (Date accessed: 26.02.2021).

3. Notman O., Bagirova A. Megapolis as an environment for reproduction and development of human capital [Electronic resource]// The 14th International Days of Statistics and Economics: Conference Proceedings. Prague, Czech Republic. - Pp. 752-761. DOI: 10.18267/pr.2020.los.223.0. - URL: https://msed.vse.cz/msed_2020/article/307Notman-Olga-paper.pdf (Date accessed: 26.02.2021).

4. Van de Kaa D. Temporarily New: On Low Fertility and the Prospect of Pro-natal Policies// Vienna Yearbook of Population Research. 2006. - Pp. 193-211.

5. Архангельский В. Н. Рождаемость и репродуктивное поведение в России период активизации поддержки семей с детьми // Демографическая и семейная политика в контексте целей устойчивого развития: сборник статей IX Уральского демографического форума. - Екатеринбург: Институт экономики УpO PAH, 2018. - T. 1. - C. 7-25.

6. Багирова А.П., Быкова Д.Г., Ворошилова А.И., Ильвес Э.В., Черешова С.В. Родительский труд: экономический и социологический анализ. - Екатеринбург: Изд-во Уральского университета, 2017.

7. Валиахметов Р. М. Экономические и социокультурные факторы семейного поведения (на примере исследования жизненных ценностей семейных пар в Республике Башкортостан) // Социальная динамика населения и устойчивое развитие. - М.: МГУ, 2019. - C. 33-38.

8. Ильдарханова Ч. И. Семья и дети в Республике Татарстан: парадоксы общественного сознания // Научный Татарстан. - 2018. №3. - C. 11-16.

9. Клупт М.A. Демография регионов Земли. - СПб.: Питер, 2008.

10. Кулькова И.А. Весомость повышения пенсионного возраста как фактора сокращения рождаемости // Институты развития человеческого потенциала в условиях современных вызовов. Сборник статей XI Уральского демографического форума. - Екатеринбург: Институт экономики УрО РАН, 2020. - C. 154-160.

11. Кучмаева О.В. Современные проблемы оценки эффективности семейной полити- 
ки в Российской Федерации [Электронный ресурс] // Статистика и Экономика. — 2017. №5. - С. 85-93. - Режим доступа: https://doi. org/10.21686/2500-3925-2017-5-85-93.

12. Кучмаева О.В., Ростовская Т.К. Семья в системе социальных институтов общества. - М.: Юрайт, 2020.

13. Паспорт Национального проекта «Демография» [Электронный ресурс]. - Peжим доступа: https://mintrud.gov.ru/ministry/ programms/demography (Дата обращения: 26.02.2021).

14. Шмарова И.В. Изучение прямых затрат родительского труда: потенциал и ограничение исследовательских методов // Развитие территориальных социально-экономических систем: вопросы теории и практики: материалы XVI международной научно-практической конференции молодых ученых. - Екатеринбург: Институт экономики УpO РAH, 2019. - C. 237-240.

15. Шмарова И.В. Родительский труд как потенциальный инструмент демографической политики // Достойный труд - основа стабильного общества: материалы X Международной научно-практической конференции. - Екатеринбург: Изд-во УрГЭУ, 2018. - C. 156-160.

16. Шубат O.M. Региональная конвергенция рождаемости в России // Экономика региона. - 2019. - Т. 15. - Вып. 3. С. 736-748.

17. Шутова Н. В. Социальная эффективность стимулирования родительского труда работников организации: методика оценки и результаты // Вестник экономики, права и социологии. - 2020. - №2. - С. 186-191.

18. Юферева А.С., Ворошилова А. И. Особенности влияния медиаконвергенции на формирование образа родительства (по итогам контент-анализа социальных сетей) // Стратегии развития социальных общностей, институтов и территорий: материалы IV Международной научно-практической конференции: в 2-х т. - Екатеринбург: Изд-во Уральского университета, 2018. - Т. 1. - С. 132-136.

\section{References}

1. Demeny P. Population Policy // International Encyclopedia of Population. - New York, MacMillan Reference, 2006. - Pp. 752-763.
2. KoslowskiA., Blum S., Dobrotić I., Kaufman G., Moss P. International Review of Leave Policies and Research 2020 [Electronic resource]. - URL: http://www.leavenetwork.org/ lp_and_r_reports/ (Date accessed: 26.02.2021).

3. Notman O., Bagirova A. Megapolis as an environment for reproduction and development of human capital [Electronic resource] // The 14th International Days of Statistics and Economics: Conference Proceedings. - Prague, Czech Republic. - Pp. 752-761. - DOI: 10.18267/ pr.2020.los.223.0. — URL: https://msed.vse.cz/ msed_2020/article/307-Notman-Olga-paper.pdf (Date accessed: 26.02.2021).

4. Van de Kaa D. Temporarily New: On Low Fertility and the Prospect of Pro-natal Policies// Vienna Yearbook of Population Research. 2006. - Pp. 193-211.

5. Arhangel'skij V.N. Rozhdaemost' i reproduktivnoe povedenie $\mathrm{v}$ Rossii period aktivizacii podderzhki semej s det'mi [Birth rate and reproductive behavior in Russia the period of activation of support for families with children] // Demograficheskaja i semejnaja politika v kontekste celej ustojchivogo razvitija: sbornik statej IX Ural'skogo demograficheskogo foruma [Demographic and family Policy in the context of the Sustainable Development Goals: a collection of articles of the IX Ural Demographic Forum]. - Ekaterinburg: Institut jekonomiki UrO RAN, 2018. - Vol. 1. - Pp. 7-25.

6. Bagirova A.P., Bykova D. G., Voroshilova A.I., Il'ves Je. V., Chereshova S. V. Roditel'skij trud: jekonomicheskij i sociologicheskij analiz [Parental work: economic and sociological analysis]. - Ekaterinburg: Izd-vo Ural'skogo universiteta, 2017.

7. Valiahmetov R.M. Jekonomicheskie i sociokul'turnye faktory semejnogo povedenija (na primere issledovanija zhiznennyh cennostej semejnyh par v Respublike Bashkortostan) [Economic and socio-cultural factors of family behavior (on the example of the study of the life values of family couples in the Republic of Bashkortostan)] // Social'naja dinamika naselenija i ustojchivoe razvitie [Social dynamics of the population and sustainable development]. Moscow: MGU, 2019. - Pp. 33-38.

8. Il'darhanova Ch. I. Sem'ja i deti v Respublike Tatarstan: paradoksy obshhestvennogo soznanija [Family and children in the Republic of Tatarstan: paradoxes of public conscious- 
ness]// Nauchnyj Tatarstan [Scientific Tatarstan]. — 2018. — №3. - Pp. 11-16.

9. Klupt M.A. Demografija regionov Zemli [Demography of the Earth's regions]. - Saint Petersburg: Piter, 2008.

10. Kul'kova I.A. Vesomost' povyshenija pensionnogo vozrasta kak faktora sokrashhenija rozhdaemosti [The weight of raising the retirement age as a factor in reducing the birth rate] // Instituty razvitija chelovecheskogo potenciala $\mathrm{V}$ uslovijah sovremennyh vyzovov. Sbornik statej XI Ural'skogo demograficheskogo foruma [Institutions of human development in the context of modern challenges. Collection of articles of the XI Ural Demographic Forum]. - Ekaterinburg: Institut jekonomiki UrO RAN, 2020. Pp. 154-160.

11. Kuchmaeva O.V. Sovremennye problemy ocenki jeffektivnosti semejnoj politiki V Rossijskoj Federacii [Modern problems of evaluating the effectiveness of family policy in the Russian Federation] [Jelektronnyj resurs] // Statistika i Jekonomika [Statistics and Economics]. 2017. — №5. - Pp. 85-93. — URL: https://doi. org/10.21686/2500-3925-2017-5-85-93.

12. Kuchmaeva O.V., Rostovskaja T.K. Sem'ja v sisteme social'nyh institutov obshhestva [The family in the system of social institutions of society]. - Moscow: Jurajt, 2020.

13. Pasport Nacional'nogo proekta «Demografija» [Passport of the National project «Demography»] [Jelektronnyj resurs]. — URL: https://mintrud.gov.ru/ministry/programms/demography (Date accessed: 26.02.2021).

14. Shmarova I. V. Izuchenie prjamyh zatrat roditel'skogo truda: potencial i ogranichenie issledovatel'skih metodov [The study of direct costs of parental labor: the potential and limitation of research methods] // Razvitie territorial'nyh social'no-jekonomicheskih sistem: voprosy teorii i praktiki: materialy XVI mezhdunarodnoj nauchno-prakticheskoj konferencii molodyh uchenyh [Development of territo- rial socio-economic systems: questions of theory and practice: materials of the XVI International scientific and practical conference of young scientists]. - Ekaterinburg: Institut jekonomiki UrO RAN, 2019. - Pp. 237-240.

15. Shmarova I. V. Roditel'skij trud kak potencial'nyj instrument demograficheskoj politiki [Parental labor as a potential tool of demographic policy] // Dostojnyj trud - osnova stabil'nogo obshhestva: materialy X Mezhdunarodnoj nauchno-prakticheskoj konferencii [Decent work - the basis of a stable society: proceedings of the $\mathrm{X}$ International Scientific and Practical Conference]. — Ekaterinburg: Izd-vo UrGJeU, 2018. - Pp. 156-160.

16. Shubat O.M. Regional'naja konvergencija rozhdaemosti v Rossii [Regional convergence of fertility in Russia] // Jekonomika regiona [The economy of the region]. - 2019. - Vol. 15. Issue 3. - Pp. 736-748.

17. Shutova N. V. Social'naja jeffektivnost' stimulirovanija roditel'skogo truda rabotnikov organizacii: metodika ocenki i rezul'taty [Social efficiency of stimulating parental labor of employees of the organization: evaluation methods and results] // Vestnik jekonomiki, prava i sociologii [Bulletin of Economics, Law and Sociology]. - 2020. — №2. - Pp. 186-191.

18. Jufereva A.S., Voroshilova A.I. Osobennosti vlijanija mediakonvergencii na formirovanie obraza roditel'stva (po itogam kontent-analiza social'nyh setej) [Features of the influence of media convergence on the formation of the image of parenthood (based on the results of the content analysis of social networks)] // Strategii razvitija social'nyh obshhnostej, institutov i territorij: materialy IV Mezhdunarodnoj nauchnoprakticheskoj konferencii: v 2-h t. [Strategies for the development of social communities, institutions and territories: materials of the IV International Scientific and Practical conference: in 2 volumes]. - Ekaterinburg: Izd-vo Ural'skogo universiteta, 2018. - Vol. 1. - Pp. 132-136. 


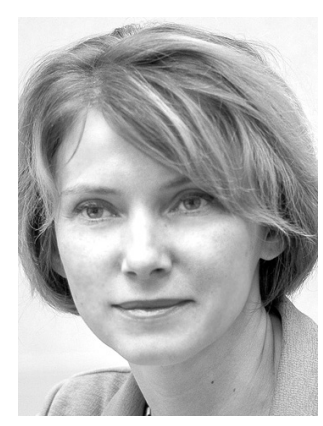

Багирова Анна Петровна - профессор, доктор экономических наук, профессор кафедры социологии и технологий государственного и муниципального управления, заместитель директора по науке и инновациям Института экономики и управления Уральского федерального университета имени первого Президента России Б.Н. Ельцина.

Bagirova Anna Petrovna - Professor, Doctor of Economic Sciences, Professor of the Department of Sociology and Technologies of State and Municipal Administration, Deputy Director for Science and Innovation of the Institute of Economics and Management, Ural Federal University named after the first President of Russia B. N. Yeltsin.

620002, г. Екатеринбург, ул. Мира, 19

19 Mira st., 620002, Yekaterinburg, Russia

E-mail: a.p.bagirova@urfu.ru 